\title{
Espelhamentos, recordações e percalços sobre a feitura de espelhos - uma teatralização dos contos "O espelho", de Machado de Assis e Guimarães Rosa
}

\section{Mirrors, Memories and mishaps about the making of Mirrors - a theatricalization of the homonymous tales The mirror of Machado de Assis and Guimarães Rosa}

Resumo: Este artigo narra a trajetória da confecção do projeto lítero-teatral Espelhos, realizado sobre os contos "O espelho", de Machado de Assis, e "O espelho", de Guimarães Rosa. Trata-se de um resgate elaborado a partir das anotações feitas durante as fases que se constituíram em um percurso - condutor do processo gerador de uma encenação leal às fontes literárias. Pessoal e objetivo, sentimental e reflexivo, Espelhamentos é a memória de um ator que foi modificado pelos materiais que escolheu.

Palavras-chave: Literatura. Teatro. Atuação.

Abstract: This article narrates the trajectory of the making of the ltero-theatrical project Espelhos, made on the tales $O$ Espelho, by Machado de Assis and O mirror de Guimarães Rosa. It is a rescue elaborated from the notes made during the phases that constituted a path-conductor of the process that generates a staging loyal to the literary sources. Personal and objective, sentimental and reflective, Mirrors is the memory of an actor who has been modified by the materials he has chosen. Keywords: Literature. Theater. Acting.

1 Professor doutor temporário do Departamento de Artes Cênicas da Escola de Comunicação e Artes da Universidade de São Paulo Universidade de São Paulo (USP). 
"Fumo bom a si se vende."

Guimarães Rosa......

\section{Resumo dos contos}

Espelhos foi como batizamos nossa transposição cênica da íntegra dos contos "O espelho", de Machado de Assis (publicado em 1882 no livro Papéis Avulsos) e "O espelho”. de Guimarães Rosa (publicado em 1962 no livro Primeiras Estórias). No de Machado de Assis, vemos Jacobina assumir uma identidade externa a ele, a ponto de, por uma ocasião inesperada, fantasmagoricamente perdê-la quando deixa de ser tratado como um Alferes da Guarda Nacional do Segundo Império brasileiro. Em Guimarães Rosa, deparamo-nos com um inidentificável cidadão que se debate à procura de suas feições, até vislumbrar em si alguma humanidade.

\section{Antes}

Desde que meu filho Ébano, vindo do colégio em 1998, depositou em sua cama Memórias Póstumas de Brás Cubas, voltei a ler Machado de Assis para não mais parar. Eu já estava na Companhia do Latão², que pesquisava sobre o teatro dialético de Bertolt Brecht, e identifiquei em Assis correspondências com o dramaturgo alemão: o narrador negativo, com quem não há identificação (Brás Cubas não é nada edificante); a fala direta ao público - "A obra em si mesma é tudo: se te agradar, fino leitor, pago-me da tarefa; se te não agradar, pago-te com um piparote, e adeus." (ASSIS, 1882, p. VI); acrescidos da ironia e da desfaçatez de classe, entre outros pontos. Com a substancial diferença de que Machado de Assis fora brasileiro e seus temas tão nativos. Não seria exagero dizer que no autor de Dom Casmurro enxergamos as origens da má constituição do Brasil e a

2 Grupo teatral paulistano ao qual pertenço desde a sua fundação em 1997. 
consequente deformação de seus indivíduos.

De modo que ao me aproximar deste autor, sem sucesso procurei transferir algumas de suas obras para outras linguagens, como o cinema, experimentei utilizá-las em exercícios na própria Companhia do Latão ${ }^{3}$, estudei seus comentadores, até me limitar a "O espelho". Por intuição ou por ele guardar uma síntese machadiana. Antes de me decidir por tentar realizá-lo teatralmente, igualmente me eduquei sobre seus atributos literários pelas mãos de teóricos e conhecedores. No final de 2014, propus à diretora Vivien Buckup indagarmos cenicamente a respeito deste conto referencial da literatura brasileira e, no dia sete de janeiro de 2015, entramos em sala de ensaios. Guiados pelo desejo e sem nenhum recurso econômico, iniciamos a jornada para conferir se a história de Jacobina daria bom teatro ou não. Seguiríamos se aquilo fizesse sentido para nós. Caso contrário, abandonaríamos tal pretensão.

\section{Verão}

Naquele primeiro mês, houve basicamente quatro movimentos. A memorização parcial do conto, ainda que a direção não a tivesse recomendado. Curioso que mesmo possuindo um histórico como ator de não precipitar a fixação de um texto, naquele caso, pela insegurança por estar diante de um considerável volume de palavras, gradativamente decorei o seu teor. Simultaneamente, houve o trabalho físico de Vivien Buckup sobre mim, dado o seu conhecimento sobre a matéria: respirações acopladas a alongamentos cuidadosos e à correção de posturas. De fato, uma especial aplicação, cuja impressão foi a de estar trabalhando corporalmente bem mais do que a minha média.

Não faltaram a estes encontros diversificadas leituras do conto

3 Durante as experimentações feitas para o espetáculo Visões siamesas (2004), que uniu Machado de Assis a Bertolt Brecht. 
com a distinção de fonemas (a exemplo de "U" de "L" e " $D$ " de "T") ou falar o seu conteúdo sem pontuações, evitando interpretações imediatas, como a associação de uma voz soturna a passagens sombrias da fábula.

Como lhe era habitual, Machado de Assis não economizou em erudição e, por dever e prazer, em casa me ilustrava repassando os autores citados em "O espelho": Luís de Camões, William Shakespeare, Charles Perrault, Henry Wadsworth Longfellow ou a Bíblia. Mesmo que o autor os utilizasse em apenas uma frase na história, eu haveria de ler os seus livros inteiros. E depois de conhecê-los, era distinta a emissão dos trechos em cena: havia espessura no que eu dizia. À parte, li $O$ mito de Sísifo, de Albert Camus ${ }^{4}$ - um presente da diretora, que também me abasteceu com alguns filmes documentários sobre notórios escritores brasileiros ${ }^{5}$, para que eu me circundasse da atmosfera literária nacional. Quem sabe, sem que se programasse, algo de indireto surgisse dessas fontes tangenciais.

Em uma manhã de fevereiro, em que o aquecimento transmitido a mim pela diretora foi mais longo, associei as peculiaridades do texto aos pequenos movimentos corporais que separavam os dedos do restante dos pés, os pés dos calcanhares, as canelas dos joelhos e estes das coxas, o que se poderia estender aos quadris com suas divisões. Era como se, da partição dos meus membros, eu viesse a penetrar nos esconderijos das frases e descobrisse suas escavações, seus respiros.

Em continuidade à memorização do texto, para a estranheza de quem estivesse por perto, treinava-o por onde quer que fosse: cedo na academia de ginástica (antes mesmo de ir aos ensaios), andando pelas ruas, nos parques, cozinhando, escrevendo ou mesmo chegando com uma hora de antecedência à sala de trabalho. Em uma noite, eu estava só na casa de um amigo fora da cidade. Quando fui ver a lua e as estrelas, e para que uma luz artificial que vinha da estrada não roubasse a natural,

\footnotetext{
4 Este, quem sabe, sobre as possíveis correspondências entre as incertezas da vida como artistas.

5 Manuel Bandeira, Jorge Amado, Ledo Ivo, entre outros.
} 
procurei uma sombra noturna entre as plantas do jardim e passei a narrar parte do texto naquele quintal, simulando o isolamento do personagem em estudos: "Ninguém nas salas, nos corredores, na varanda, no terreiro, ninguém em lugar algum...." (ASSIS, 1882, p. 252). Projetei ficar alguns dias totalmente sozinho em um sítio, como acontecia com Jacobina no argumento, mas não cheguei a tanto.

Com o passar das semanas, eu já me descolava das folhas de papel e me impelia, limitadamente, a atuar sobre certos parágrafos. E entre as solicitações da direção, estava a de que eu não utilizasse as mãos e os braços ao performar as palavras de Machado de Assis (o que, por sua vez, me levava a tensionar ombros e pernas). Trôpego, prosseguia. Pertinente também foi outro apontamento da diretora de que quando me desorientei em cena, alguma vida apareceu. Deixar-se levar. Isso para quem ainda prendia os nervos como eu, não era simples. Por outro lado, os estudos teóricos sobre "O espelho" se dilataram com a absorção de Antonio Candido, Alfredo Bosi, John Gledson, Dante Moreira Leite, Suzana Kampff, Luiz Roncari, Edna Maria F. S. Nascimento e Maria Célia Leonel, sendo que estas duas últimas traziam um estudo comparativo com o conto correspondente de Guimarães Rosa.

$\mathrm{Na}$ lida, as improvisações nos governavam para intentarmos dar forma teatral àquela literatura, transformando as cadeiras disponíveis na sala até nos amigos de Jacobina. E cheguei a arrancar o tampo de uma mesa, encostando-o verticalmente na parede para que ele se transformasse em um espelho. Entretanto, meus defeitos teimavam em não me deixar: não percorria os movimentos e seguia bruscamente dos seus inícios aos seus fins, suprimindo os meios. Uma atuação staccata ${ }^{6}$. Somadas aos desenganos anteriores - pescoço caído à frente, ombros repuxados e o andar suspenso, eu desanimava. $O$ grau de exigência não era pequeno, todavia

\footnotetext{
6 O staccato diz respeito a uma musicalidade com intervalos entre as notas, sem necessariamente uma continuidade sonora. Ou seja, interrompida.
} 
Vivien Buckup operava sobre o meu corpo para que ele se modificasse, pouco que fosse. Minha interrogação era a de se um homem de 55 anos teria como se transformar. Tanto queria que, paralelamente, praticava Yoga, academia, psicanálise e entrara nos laboratórios do diretor Antunes Filho e da atriz e professora doutora Lúcia Romano7, cujas premissas eram bem distintas das que eu conhecia até então.

Como trazia sempre comigo o livro Papéis Avulso (o qual continha "O espelho"), associei certas figuras dos outros contos ao nosso universo: "D. Benedita" teria traços da Tia Marcolina, o Major de "A chinela turca" se passaria por um dos comparsas da casa-cenário da obra. Quanto mais esquadrinhava, novas lacunas se apresentavam para serem completadas: como eram os parentes mais próximos do anti-herói, qual foi a sua formação escolar? Mesmo sendo infinita a feitura de um personagem, eu procurava levantar o maior número de dados sobre ele.

\section{Abril de 2015}

Enquanto pretendia dar fluxo cênico à narração, deparava-me com senões: elocução acelerada das frases e, em boa parte dos ensaios, o corpo fechado e o rosto crispado. Isso se passava, quem sabe, pela falta de intimidade junto ao conto, o que melhoraria com o tempo.

Fora da sala, lia e relia sobre o mundo machadiano. Pelas crônicas do autor, eu enxergava o Rio de Janeiro de então em suas peculiaridades: como agiam seus comerciantes, quais eram os discursos políticos do período e como sua gente simples se portava nas ruas. Era como se eu fosse desenhando um mapa imaginário, cada vez mais povoado de

\footnotetext{
7 O CPTzinho (Centro de Pesquisa Teatral) é um curso de três meses em que seus participantes adquirem noções do método atoral desenvolvido por Antunes Filho. Justamente seus exercícios físicos me eram os mais problemáticos. O LAPCA: Laboratório de Processos de Criação Atorais da UNESP - Universidade Estadual Paulista, coordenado por Lúcia Romano, reforçava a procura por saberes desconhecidos por mim. Ressalte-se que tais frequências se davam também em função das pesquisas para o meu doutorado em pedagogia teatral na Universidade de São Paulo, através de uma Bolsa de Estudos da CAPES-CNPq.
} 
características daquela segunda metade do século XIX. Por outra via, recuei até Sérgio Buarque de Holanda em seu O Brasil Monárquico - Do Império à República, de onde anotei que o tempo de Jacobina era o da escravidão, o da Guerra do Paraguai e o do sufrágio universal. Aprendia sobre como nos fizemos e, consequentemente, o que constituíra meu personagem.

\section{Maio}

Guimarães Rosa nos desassossegava. Havíamos lido o seu "O espelho" por ele constar em comparações sobre as duas criações, nas quais se ventila que Guimarães Rosa escrevera, oitenta anos depois, uma resposta a Machado de Assis ${ }^{8}$. Nosso intuito sempre fora fazer apenas o texto do mestre carioca e, mesmo assim, com dúvidas de que seríamos capazes de teatralizá-lo. O conto do autor mineiro nos parecia ainda mais complexo para encená-lo. Muito embora eu tenha chorado enquanto lia a revelação final das desditas da figura roseana. Fomos incitados pela possibilidade de unir no palco as diferentes sensibilidades dessas duas matrizes da literatura brasileira. E quanto mais nos víamos como incapazes também de verter Guimarães Rosa e o seu “O espelho" ao tablado, mais improvisávamos sua rebuscada invenção.

No quinto mês de ensaios, já tínhamos um traçado teatral do que Machado de Assis escrevera. E era somente comigo, três cadeiras e uma escrivaninha.

Para não ser leviano ao representar dois dos maiores escritores do país e diante do anseio de dar vida às vinte páginas corridas de expressões elaboradas, procurei por Mônica Montenegro, fonoaudióloga e professora de voz. Com ela, tive aulas em que todo o meu corpo se mobilizava para

\footnotetext{
8 "Não é descabido postular que ele tenha escrito o conto homônimo para enfrentar a ironia cósmica do Bruxo do Cosme Velho no limite entre as figurações da crença e da descrença.” (WISNIK, 2014)
} 
um composto preparo respiratório e vocal. Adensavam-se assim as técnicas que se desdobrariam, no correr do processo, em predicados artísticos.

Abaixar os ombros, relaxar a testa, não encolher o queixo e transferir alternadamente o peso para os pés e pernas ao andar. Os parâmetros da direção se revelavam avançados para mim, cujo repertório pessoal estava aquém do solicitado.

Como estímulo para uma interpretação não realista, com a qual rondávamos o conto "O espelho" de Guimarães Rosa, Vivien Buckup me emprestou um vídeo repleto de estranhos e esquisitos animais. Vi-o mais de uma vez, e jogamos a partir dele, comigo me revirando feito aqueles bichos e, ao mesmo tempo, soltando o segundo texto. Com o passar das semanas, esquecemos aquelas contorções para que elas, um ano depois da peça estreada, voltassem em traços que longinquamente lembravam as imprecisas imitações animalescas.

\section{Inverno}

A absorção dos vocábulos em Guimarães Rosa foi custosa. Neologismos, inversões gramaticais, inusuabilidades léxicas. Literatura sinuosa e cortante. Caudalosa e delicada. Contudo, o repto maior foi transferir, do livro à cena, a metafísica roseana. No ordinário dos trabalhos, houve lá um repente nas investidas, em que tirei a camisa que usava na parte machadiana, dei-lhe nós e a joguei, como quem se desfaz de algo que o aflige. Depois comecei a descascar da primeira, uma outra roupa, formada por uma calça velha que ia só até as canelas e uma camisa regata batida.

Em um determinado momento, Vivien Buckup pediu para eu me ausentar no dia seguinte, pois ela iria planificar a segunda parte do nosso propósito. Assim, ao reparar que, em traço grosso, tínhamos os dois contos no palco, alegrei-me. Afinal, sequer sabíamos se aquela transposição seria 
exequível. Suscintamente, a encenação que se apresentava como fixa em Machado de Assis, paulatinamente se desmontaria em Guimarães Rosa. Uma simples concepção que ganharia respiros com pequenos pecados.

Em outro plano, sem que planejasse, passei a ler as obras de Guimarães Rosa e com elas me emocionava, a exemplo da novela "A estória de Lélio e Lina" (de Corpo de baile), "Manoelzão e Miguelim" e até mesmo "Sorôco, sua mãe e sua filha" ou "A terceira margem do rio" (também de Primeiras Estórias). E o fazia nos crepúsculos, em que se desenhavam no céu da minha janela uma beleza diferente a cada tarde-noite. Bem mais adiante, quando a peça feita percorria diversos lugares, elaborei que o procedimento junto a Machado de Assis pendeu à compreensão e, a Guimarães Rosa à sensibilização.

Entrara em nosso radar o artigo de José Miguel Wisnik: "Psiquê e psichê: no encontro dos espelhos de Machado e Rosa". Nele, o músico e professor de literatura considera o homem de Guimarães Rosa um "amalucado". Lá fui eu dar ares de louquinho ao tipo do segundo "O espelho". Investimento frustado, como se poderia esperar. Com o espetáculo em cartaz, isto chegou a acontecer, mas quando sequer me lembrava da indicação de Wisnik. Saliento: ao me deixar conduzir pela criatura de Guimarães Rosa, suas características foram surgindo - o que era diferente de imprimir-lhe precipitadamente ares de maluco.

Todavia, considerava a concentração, sem nenhum colega ao lado (por ser um solo cênico), a menos acessível das faculdades atuativas. Absorver-se em projetos nos quais contracenamos com parceiros tem lá suas exigências, entretanto com todas as incumbências recaindo apenas sob minha responsabilidade, via-me arriscando como nunca.

Sob o signo das reelaborações, tínhamos já uma planta geral da nossa tridimensionalização literária. Assim sendo, haveríamos de nos voltar às particularidades, como a do meu olhar para o conto de Machado de Assis, que carecia de direcionamento. De acordo com a direção, em 
Guimarães Rosa, ao me desfazer das primeiras peças do vestuário, eu as prendia próximas ao corpo. Em contrapartida, registro que diminuíra o infortúnio de trabalhar sem ninguém, quando a diretora não estava. Aquilo não era apenas artístico e sim uma confirmação de que a ansiedade, a falta de autonomia, de introspecção que em mim grassavam, não eram absolutamente incontornáveis.

Em um sábado à tarde, fui à biblioteca do Centro Cultural São Paulo para folhear $A$ história da vida privada no Brasil, v. 2. Desejava povoar o imaginário de Jacobina com as pessoas daquele período histórico, com as moradias (modestas e robustas), vestimentas e objetos domésticos e assim por diante. O que antes era tímido - não me limitar às circunstâncias textuais sobre os meus papéis, agora se estendia a um inventário imagético maior: pinturas, fotografias, o que me fez passar a desenhar certas passagens sobre o meu personagem. $\mathrm{O}$ meu traço era rudimentar, todavia rabiscar expandia meus horizontes e não apenas da figura em idealização.

Era o tempo de viver o ofício por inteiro. Cedo, a meditação e em seguida a academia. A caminho dos ensaios, memorização dos textos e, às tardes, Yoga, massagens, aulas de voz, leituras e pesquisas, incluindo os laboratórios coordenados por Antunes Filho e Lúcia Romano. Dificilmente voltarei a viver um ciclo como aquele, em que a preparação atoral raspou a plenitude.

Chegara a primavera. Sem agenda para a estreia e com o temor de malograr, pedia a um ou dois amigos que fossem assistir ao que até então havíamos produzido. Carentes de aprovação, meus olhos talvez transparecessem um certo desespero. E, ao recordar depois os comentários favoráveis daqueles espectadores, eu retesava. "Foram condescendentes porque perceberam minha vulnerabilidade." Mesmo assim, sentia-me "em cartaz" fazendo uma ou mais apresentações por semana para um público rarefeito, antes do verão crescer. 


\section{Quase um ano depois}

Ficamos sem atividades práticas até outubro de 2016, procurando meios para viabilizarmos a volta do projeto. Após muitas investidas, fomos selecionados em um edital público9. Na retomada dos ensaios, uma dominante foi a desassociação/associativa das palavras e gestos na encenação do conto de Guimarães Rosa. Como quando tirava o sapato (desamarrando-o), enquanto dizia: "O experimento, por sinal ainda não realizado com rigor, careceria de valor científico em vista das irredutíveis deformações de ordem psicológica." (ROSA, 2001, p. 77) Acudimos a esse expediente como um paralelismo a determinadas passagens do texto. As expressões orais em Guimarães Rosa seriam acompanhadas por desfazimentos da cenografia e das roupas, desencobrindo um outro ambiente para o segundo personagem. De maneira que o que estava armado em Machado de Assis - elocução verbal correta com economia gestual, cenário e figurino montados - se desmanchariam (não linearmente) na parte seguinte. Um simples dispositivo que, para escapar ao esquematismo, dependeria das modulações que acrescentaríamos gradativamente ao jogo teatral.

Em relação à atuação, entrara em questão o quanto eu estava deixando de me portar como o cavalo e o cavaleiro. Pela bússola de Vivien Buckup, deveriam coexistir em mim o conduzido e o condutor, o guia e o guiado. Deparava-me com um código diverso, sobre o qual, a princípio, eu silenciava por me achar despreparado. Concordava com a diretora, embora não soubesse como realizar tais recomendações. Era, por exemplo, o que acontecia no momento em que a criatura roseana desaparecia diante do espelho, quando eu expressava a obviedade do medo pela falta da imagem.

$9 \quad 4^{\text {a }}$. edição do Prêmio Zé Renato de Teatro, da Secretaria Municipal de Cultura de São Paulo. 
Entretanto, haveria divergência em relação a Machado de Assis, sem que a figura criada por Guimarães Rosa necessariamente se assustasse com seu próprio sumiço espectral.

\section{Estreia}

Em vinte de outubro de 2016, estreamos: o nervosismo me fez tremer, visivelmente. Passava por um sem número de percalços artísticos e pessoais, e havia a sofisticação dos contos e o meu princípio como solista. A tônica da temporada inaugural foi a minha tensão. As densidades literárias me absorviam, e eu me prendia menos à arquitetura cênica organizada pela diretora, a partir das nossas experimentações, do que à elocução das frases dos autores. Depois de exibidas ao público as quinze primeiras sessões, não foi sem surpresa que soube da indicação ao Prêmio de Melhor do ano pela APCA (Associação Paulista de Críticos de Arte).

Em outro aspecto, a inviabilidade econômica fez com que a iniciativa voltasse a cartaz somente treze meses após o seu lançamento. De todos os esforços para continuar a levar o espetáculo às pessoas, o que vingou foi a aprovação no Edital de Incentivo à Leitura em Bibliotecas Públicas Municipais pelo ProAC (Programa de Ação Cultural da Secretaria de Estado da Cultura de São Paulo). Com um valor bem modesto, mas encorajador para continuar. Foi então que algo novo apareceu na arte. Sem que eu programasse, à altura de dizer, em Guimarães Rosa, “[ ]... os movimentos translativo e rotatório desse planeta terra, sobre o que os seus e os meus pés assentam.” (ROSA, 2001, p. 80), peguei-me coçando as nádegas. Suspeitei que isso poderia ser um efeito tardio do que Vivien Buckup havia me dito sobre ser o homem roseano um rústico, no entanto não ignorante: um matuto-erudito, desconfiei. Enquanto o sujeito machadiano se caracterizaria como um pseudoliterato. Desse modo, abriase um estágio do trabalho em que as diferenças se acentuaram: o hieratismo 
de Jacobina, no primeiro conto, teria a oposição de um feitio moldável na segunda parte da encenação - relativa a Guimarães Rosa. E isso não apenas em termos estilísticos, porém como um cotejamento teatralizado em que a impostura do personagem de Machado de Assis triunfava e a busca tresloucada do vivente de Guimarães Rosa daria num ínfimo, todavia vital. Progressivamente fui inventando gestos e lances corporaisobjetais-espaciais nos quais, como a diretora já havia concebido, as falas não ilustravam as ações, contudo promoviam síncronos sentidos. O que desembocou em uma linguagem própria, a serviço dos conteúdos das obras (creio). Para citar apenas um instante, ao acomodar o paletó no chão do palco, depois de tirá-lo me desfazendo da "casca" jacobínica, levantava do piso somente a sua gola, descolando-a do chão em um frágil equilíbrio, enquanto dizia: "Sobretudo uma inembotável paciência" (ROSA, 2001, p. 79) - a respeito da infrene busca do homem de Guimarães Rosa pela sua autoimagem especular. Registro ainda que uma certa desenvoltura física se desabriu, como se todas as práticas ativadas anteriormente se reunissem em um feixe agora promotor de cruzamentos semânticos-somáticos. A exemplo da pressão que fazia a manga da camisa no braço, dando a ideia de que iria tirar sangue das veias aparentes, ao falar:

"E, em seguida, o que se deveria ao contágio das paixões, manifestadas ou latentes, o que ressaltava das desordenadas pressões psicológicas transitórias. E, ainda, o que, em nossas caras, materializa idéias e sugestões de outrem; e os efêmeros interesses, sem seqüência nem antecedência, sem conexões nem fundura." (ROSA, 2001, p. 81).

Discordâncias entre gestos e falas que, entretanto, cruzavam-se em assimetrias não de todo despropositadas. A ponto de, na última temporada de Espelhos no Rio de Janeiro, o crítico do jornal O Globo reclamar: “...não raro a movimentação excessiva e certo brilho de loucura nos olhos do ator 
atrapalham a compreensão de passagens cruciais do conto." (PESSOA, 2019, p. 7). Era preciso conter os exageros derivados das descobertas intrínsecas àqueles sedutores procedimentos, para preservar a literatura de Guimarães Rosa, tendo em vista sermos conscientes de estarmos a serviço dos autores e não o contrário.

Por último, dei-me conta que redundava, grifando os sentimentos no desfecho do autor mineiro. Desnecessário demonstrar que o personagem estava tocado em: "Por um certo tempo, nada enxerguei. Só então, só depois: o tênue começo de um quanto como uma luz, que se nublava, aos poucos tentando-se em débil cintilação, radiância. Seu mínimo ondear comovia-me, ou já estaria contido em minha emoção?” (ROSA, 2001, p. 82) Bastava fluir as palavras e nada mais, sem vincá-las.

Esta aventura existencial e artística me transformou como ator e como pessoa, o que intensificou a minha revolução íntima. Se Guimarães Rosa fez de mim alguém amoroso, Machado de Assis me ensinou que somos um povo dependente do que vem de fora e que na nossa terra vencem os que assumem o embuste social. $O$ escritor que mais me acompanhou na vida foi Machado de Assis, sem dúvida. Entretanto, depois de ter personificado uma pequena fração dos dois, tornei-me também um seguidor de Guimarães Rosa, em busca de um nada que seja alguma coisa.

\section{Referências}

ALENCASTRO, Luiz Felipe de (org.). História da vida privada no Brasil, v. 2. São Paulo: Companhia das Letras, 1997.

ASSIS, Machado de. Memórias Póstumas de Brás Cubas. Rio de Janeiro: Tipografia Nacional, 1882.

. Papéis Avulsos. Rio de Janeiro: Lombaerts \& C., 1882.

CAMUS, Albert. O mito de Sísifo. Rio de Janeiro: Record, 2004. 
HOLANDA, Sérgio Buarque. História Geral da Civilização Brasileira. Tomo II O Brasil Monárquico. Volume 7 Do Império a República. Rio de Janeiro: Editora Bertrand Brasil, 2005.

PESSOA, Patrick. Machado de Assis e Guimarães Rosa como dramaturgos.

O Globo, Segundo Caderno. Crítica. Rio de Janeiro, 12 jan. 2019, p. 7. ROSA, João Guimarães. Corpo de baile. São Paulo: José Olympio, 1956. . Primeiras Estórias. Rio de Janeiro: Editora Nova

Fronteira, 2001.

WISNIK, José Miguel. Psiquê e psichê: no encontro dos espelhos de Machado e Rosa. https://joaocamillopenna.files.wordpress.com/2014/02/ wisnik-josc3a9-miguel-psiquc3aa-e-psichc3aa-no-encontro-de-machadoe-rosa.pdf, 26/03/2019.

Artigo recebido em: 29/09/2019

Aprovado em: 19/05/2020 